\title{
COVID-19 Pandemic: A Compressive Review on Gender, Herd Immunity, and Physiological Mechanisms
}

This article was published in the following Dove Press journal: Risk Management and Healthcare Policy

\author{
Tariku Sisay $\mathbb{( D}^{\prime}$ \\ Tesfaye Tolessa $\mathbb{D}^{2}$ \\ 'Department of Biomedical Sciences, \\ College of Health Sciences, Mizan Tepi \\ University, Mizan, Ethiopia; ${ }^{2}$ Department \\ of Physiology, Faculty of Medicine, \\ College of Health Sciences, Addis Ababa \\ University, Addis Ababa, Ethiopia
}

Background: Researchers and scientists experienced the spread and aid recovery of the COVID19 pandemic with a condition of great uncertainty. With limited understanding of SARS-CoV-2, current attempts at controlling its spread are focused on the suppressing approach (to reduce a sustained endogenous transmission) and the mitigating approach (to reduce the growth rate of the epidemic). On the one hand, while there has been no firm explanation, many governments have considered immunity passport and herd immunity for paths out of restrictive physical distancing measures imposed to control the spread of SARS-CoV-2 but were not successful.

Purpose of Review: Herein, we attempted to systematize the lessons and shreds of evidence related to the spectrum of illness, the physiological mechanisms of host susceptibility, herd immunity, immunity passport, gender disparities, and severe challenges and uncertainties posed by the COVID-19 pandemic. We hope that the insights provided in this review will help raise the effectiveness of the treatment policies and preventive measures required to end the pandemic.

Recent Findings: The use of immunity passports is suggested to certify an individual at low risk of acquiring or transmitting SARS-CoV-2. But, an individual might nevertheless carry the virus at similar levels and for a similar duration to those previously uninfected, with an unchanged potential for transmission. Vaccine-induced herd immunity is a complex issue inherent to a vaccine and the population receiving the vaccine. The central epidemiological questions about are as follows: what proportion of the population should be vaccinated to meet elimination (in a local program), eradication (in a global program) or a defined level of control? How is this affected by demographic factors (such as gender)? What is the best age at which to immunize? Besides, although age-dependent mortality risk is estimated to be higher for men and older people, such interpretation across gender, age groups, and countries, however, must be accepted with caution at present.

Summary: COVID-19 has taught us that health is the basis of global wealth and international solidarity is an essential response and a superior approach to isolationism. Hence, we must be clear about what the alternatives are when evaluating the merits of different ways of tackling this pandemic both in the short term as well as in the long term.

Keywords: COVID-19, coronavirus, SARS-CoV-2, gender disparity, herd immunity, immunity passport, vaccine

\section{Introduction}

A pandemic caused by different pathogens has forced citizens around the world to face and reconsider the high social and economic costs of epidemic control. A "Pandemic" is an epidemic occurring worldwide or over a wide area, crossing boundaries of
Department of Biomedical Sciences College of Health Sciences, Mizan Tepi University, Mizan, Ethiopia

Tel +251923932729

Email kaluptrk@gmail.com
Risk Management and Healthcare Policy 2020:13 2963-2974

mit your manuscript DovePress if in $v$ http://doi.org/10.2147/RMHP.S276342 
several countries, and usually affecting many people. ${ }^{1}$ It has been believed that every 100 years, a pandemic call for global concern. It is not a question of if, but when. For instance, so far in the history of the world, three pandemic outbreaks were noticed; in 1720 the Plague, in the 1820 Cholera outbreak, in 1920 Spanish Flu. ${ }^{2,3}$ The end of 2019 saw the emergence of severe acute respiratory syndrome coronavirus 2 (SARS-CoV-2) and its associated disease, COVID-19; which initially appeared in Wuhan, Hubei Province, China ${ }^{4,5}$ has become an ongoing and the biggest threat in living memory to health and wellbeing, social welfare, and the global economic system strain.

Since the mid-1960s to date, six species of human coronavirus are known, with one species subdivided into two different strains. There are four described genera of coronaviruses $(\alpha, \beta, \delta$, and $\gamma) .{ }^{6}$ Epidemics of $\beta$-coronavirus genus includes severe acute respiratory syndrome coronavirus (SARS-CoV) outbreak of 2002 to 2003, the Middle East respiratory syndrome (MERS-CoV) of 2012. ${ }^{7}$ COVID-19, a subfamily of the $\beta$-coronavirus which belongs to a large family of positive-sense single-stranded RNA; and also called SARS-CoV-2 as it shares higher genomic similarities (96\% or $89 \%$ ) with SARS-CoV. ${ }^{5}$

The SARS-CoV-2, similarly to other coronaviruses, is mainly transmitted through contact, respiratory droplets, and the potential route of fecal-oral (Table 1).$^{8-11}$ Factors such as climate, population structure, social practices, pre-existing immunity, and many other variables were noted to play a significant role in intensifying a dynamic transmission of SARS-CoV-2. ${ }^{12}$

Since scientific publications addressing the pandemic are being produced rapidly, including gender disparities, immunity passport, herd-immunity, and risk factors, summarizing and sharing such information is of paramount importance to support an efficient and rapid response. Therefore, we have compiled summary of the literature evaluating these data for COVID-19.

\section{Search Strategy and Selection Criteria}

Herein, we attempted to systematize the lessons and shreds of evidence related to the spectrum of illness, the physiological mechanisms of host susceptibility, herd immunity, immunity passport, gender disparities, and severe challenges and uncertainties posed by the COVID-19 pandemic. References for this review were identified through searches of PubMed and MEDLINE for articles published through
Table I Known Transmission Routes of COVID-I9/SARS-CoV-2

\begin{tabular}{|c|c|}
\hline Factors & Available Information \\
\hline $\begin{array}{l}\text { Respiratory } \\
\text { droplets }\end{array}$ & $\begin{array}{l}\text { Through coughs, sneezes, or ordinary talk. } \\
\text { Worryingly, detection of viral loads in the upper } \\
\text { respiratory tract suggests potential for pre- and } \\
\text { ogliosymptomatic transmission }\end{array}$ \\
\hline $\begin{array}{l}\text { Contact } \\
\text { transmission }\end{array}$ & $\begin{array}{l}\text { From object contaminated with the virus and } \\
\text { subsequent touch their mouth, nose, or eyes. }\end{array}$ \\
\hline $\begin{array}{l}\text { Aerosol } \\
\text { transmission }\end{array}$ & $\begin{array}{l}\text { As the virus-containing aerosol may reside for } \\
\text { hours in a relatively closed environment, } \\
\text { respiratory droplets mix into the air, forming } \\
\text { aerosols and may cause infection when inhaled high } \\
\text { doses of aerosols into the lungs. }\end{array}$ \\
\hline $\begin{array}{l}\text { Possibly via } \\
\text { fecal-oral }\end{array}$ & $\begin{array}{l}\text { Transmission through the gastrointestinal tract is } \\
\text { also claimed from the point of view of abdominal } \\
\text { discomfort and diarrhea symptoms. }\end{array}$ \\
\hline
\end{tabular}

November 2020, using the Medical Subject Headings terms "SARS virus", "coronavirus", "systemic inflammatory response syndrome", "child and COVID-19", "adolescent and COVID-19" "gender and coronaviruses", "herd immunity", "clinical findings," "clinical characteristic," "novel coronavirus," "covid-19," "SARS-Cov-2," "death," "mortality," "disease severity," "risk factor", "gender disparity", "uncertainties" and any relevant entry terms and supplementary concepts. Relevant articles and commentaries were also identified through searches in Google Scholar, WHO, Centers for Disease Control and Prevention, the Johns Hopkins Center for Systems Science and Engineering site for Coronavirus COVID-19 Global Cases, and other websites. Ongoing and planned clinical trials were identified using the search term "COVID-19" on the ClinicalTrials. gov website. Articles resulting from these searches and relevant references cited in those articles were reviewed. Articles published in English were identified and included.

\section{COVID-I 9 Designation}

\section{A Bridge Host}

Emerging viruses that spread to humans from an animal host are proven to be some of the deadliest diseases known. ${ }^{12}$ It was well known that the epicenter was the Human Seafood market in the city of Wuhan, China, where bats, birds, frogs, rabbits, and snakes had frequently been sold. ${ }^{4,5}$ Although no conclusive evidence shows any traces of the SARS-CoV-2, multiple known animal viruses share significant similarities with SARS-CoV-2. For 
instance, the possibility of bats as reservoir hosts for SARS-CoV-2 has been likely due to high genomic sequences $(96 \%$ or $89 \%)$ with SARS-CoV. ${ }^{13,14}$ Similarly, a coronavirus found in Malayan pangolins shared 98\% similarity with SARS-CoV-2. ${ }^{15}$ This connection does not imply that a Pangolin or bat was bridged between the host and the virus. It is well known that coronaviruses can manage to use different mechanisms to achieve the jump to another species.

On the other hand, subsequent studies have shown that human-to-human cases were reported with no history of exposure to the market or visiting Wuhan. Germany, Japan, Vietnam, and the United States were among the countries that reported cases in patients who did not personally visit China, but contracted the virus. ${ }^{16}$ Controversy aside, some researchers continue to highlight circumstantial evidence suggesting that SARS-CoV-2 is a candidate vaccine strain escaped from a laboratory in Wuhan, China when the COVID-19 SARS protein was inserted into a coronavirus to produce a more reactogenic vaccine. ${ }^{17}$ Such an escape might have occurred via accidental infection of a lab worker who came into contact with the isolated virus, an infected lab animal, or animal waste. Concerned with intense debate regarding the exact origin of COVID-19, the WHO has launched its independent investigation towards the origin of the virus. With the exception, in most of the virus outbreaks, whatever is the intermediary host, the human-to-human transmission could be interrupted and the outbreak stops at some stage. ${ }^{12}$

\section{Physiology of Host's Susceptibility}

Viruses must enter the cells of their hosts-which can be humans - as they are not self-sustained cellular entities that carry out metabolism and reproduce. Viruses commonly generate specific cellular proteins that interfere with the immune system to either stop a response or augment one as part of their pathogenicity. Researchers have learned that coronaviruses in the SARS family, including SARS-CoV-2, achieved entry by binding between the viral spikes and host receptors such as proteins, carbohydrates, and lipids. ${ }^{18}$ The entry of the coronavirus family via specific receptors in endothelial cells of arterial and venous capillaries suppresses signaling pathways, particularly pattern recognition receptors (PRRs) such as Toll-like receptors (TLRs). ${ }^{19}$

TLRs have been dubbed the "eyes of the innate immune system" because these immune sensors recognize and bind with the unique, telltale pathogen markers, allowing the effector cells of the innate system to "see" pathogens as distinct from "self" cells. As a result of suppressing such signaling, could generate prothrombotic features that favor micro-and macrothromboembolic events (stroke, infarction, myocarditis, and pericarditis). ${ }^{20}$

The spikes of the viruses contain a region that binds to the extracellular domain of angiotensin-converting enzyme-2 (ACE2) - a functional receptor used by coronaviruses, including SARS- CoV-2 for entry into the cells of a host. ${ }^{18,19}$ ACE2 is the only recognized human homo$\log$ of ACE which cleaves the inactive peptide angiotensin I (Ang-I) to the highly potent vasoconstrictor angiotensin II (Ang-II). ${ }^{21,22}$ The production of ANG II and the subsequent binding of ANG II to its receptor are thought to increase blood pressure, inflammatory events, and fibrosis. Since its discovery in 2000, the researchers thought it would be similar to ACE and generate Ang-II. Despite their similar structure, however, ACE2 degrades Ang-II and in part, through its ability to convert angiotensin II to angiotensin 1-7 (Ang-(1-7)), it has been implicated in heart function, hypertension, and diabetes. ${ }^{23,24}$ The high incidence of cardiovascular symptoms caused by COVID19 infection might be due to a high ratio of Ang-II to Ang$(1-7) .^{25}$

The concern that has been raised by some physicians so far is whether blocking ACE2 could be one way to prevent SARS-CoV-2 virus infection. In concern, it has been proposed that whether human recombinant soluble ACE2 (hrsACE2) might be used in treating patients with COVID-19. The authors suggested that administering a hrsACE2 could trick the virus into binding with it, rather than actual ACE2 receptors. This could then protect endogenous receptors and allow them to continue to function in counterbalancing ACE, and, ideally, protect the lung and heart from damage during a viral infection. ${ }^{26}$

\section{Clinical Manifestation of COVID-I 9 Symptoms}

The symptoms are similar to those from other respiratory viruses, including fever, cough, and shortness of breath with radiographs showing invasive lesions in the lungs. ${ }^{18}$ It has been reported that patients have severe hypoxemia, reduced lung compliance, elevated pulmonary dead space, and associated non-pulmonary organ failure. A pulmonary vascular injury that in turn related to blood clots (prothrombotic), ranging from clotting of dialysis lines to 
venous thrombosis to stroke seemed to be more characteristic of COVID-19. ${ }^{27}$ This might be due to the suppression of signaling pathways by the entry of coronavirus family including SARS-CoV-2 which in turn could generate prothrombotic features which favor micro-and macrothromboembolic events (stroke, infarction, myocarditis and pericarditis).

\section{Frequency of Symptoms}

To determine the order of occurrence of common symptoms of respiratory diseases, including COVID-19 a Markov Process was indicated. Eriksson et al defined Markov Process as a stochastic sequence of events in which the likelihood of the next state only depends on the current state rather than past or future states. ${ }^{28}$ Accordingly, the most likely order of occurrence of symptoms in COVID19 are fever, cough, upper GI tract (ie nausea/vomiting) and lower GI tract (ie diarrhea). However, in SARS-CoV and MERS-CoV, the order was reported as fever, cough, lower GI tract (ie diarrhea), and then upper GI tract (ie nausea/ vomiting). ${ }^{29}$ It has been emphasized that diarrhea as an initial symptom indicates a more aggressive disease such as pneumonia or respiratory failure. ${ }^{30}$

\section{Incubation Period}

The time it takes for symptoms to appear after a person infected is known as the incubation period. COVID-19 symptoms may appear in as few as 2 days and as long as 14 days (estimated ranges vary from 2 to 10 days, 2 to 14 days, and 10 to 14 days), during which the virus is contagious but the patient does not display any symptom (asymptomatic transmission. ${ }^{30}$

\section{Distinguishing Feature}

One of the unique characteristics of coronavirus diseases (SARS-CoV, SARS-CoV-2, and MERS) in contrast with other viruses such as respiratory syncytial virus seems to have a milder course in children and youth than in adults, and the obvious question is why? In regard, several suggestions have been put forward. For instance, the less maturity of ACE2 at a younger age and significantly higher levels of certain cytokines associated with the innate immune response. ${ }^{31}$

\section{The Incidence and Severity of COVID-I 9} In the COVID-19 pandemic, "what are the risk factors for severe illness or death?" is the most emphasized question. $^{32}$ The incidence and severity of COVID-19 well correlate with men, older individuals and those with comorbidities and individuals with diabetes, cardiac disease, chronic respiratory disease, or obesity. ${ }^{33}$ This has been linked to higher density expression of ACE2 receptor and correlated with specific organ failures by corresponding clinical parameters in SARS-CoV patients. ${ }^{33,34}$ To stage the seriousness of COVID-19, Modified Early Warning Score (MEWS), has been universally accepted. MEWS is based on clinical parameters: frequency of breath, pulse rate, systolic arterial pressure, hourly diuresis, body temperature, and the state of consciousness. ${ }^{35}$ The MEWS indicates clinical manifestations of the disease by their stage of severity as follows:

Stage 1: Deviation of the frequency of breath, pulse rate, and systolic arterial pressure from the baseline and summated, giving the total score.

Stage 2: Dyspnea and/or radiologic signs of pneumonia

Stage 3: MEWS equal to and above three and/or blood oxygen saturation $\left(\mathrm{SpO}_{2}\right) 90-92 \%$ are symptomatic for severe pneumonia and the risk of failure.

Stage 4: Acute respiratory distress syndrome with the ratio between the blood pressure of the oxygen (partial pressure of oxygen, $\mathrm{PaO}_{2}$ ) and the percentage of oxygen supplied (fraction of inspired oxygen, $\mathrm{FiO}_{2}$ )] $<300$ and require respiratory support within the intensive therapy facilities.

Other supportive cares that have been given for severely ill patients involved close monitoring for signs of deterioration, conservative fluid management, giving antipyretics and/or analgesics, administering appropriate empirical therapy immediately (within an hour) of sepsis identification, and managing sepsis and septic shock by following sepsis guideline. ${ }^{36}$

\section{Proposed Diagnostic Methods for COVID-I 9}

There are many different methods for Clinical diagnosis of COVID-19 testing; commonly based on epidemiological history, clinical manifestations, and several auxiliary examinations, such as nucleic acid detection, CT scan, and immune detection technology. ${ }^{37}$ Reverse transcriptionpolymerase chain reaction (qRT-PCR), however, where specimens from both the upper respiratory tract (nasopharyngeal and oropharyngeal) and lower respiratory tract (expectorated sputum, endotracheal aspirate, or bronchoalveolar lavage) collected, are regarded as an efficient method for confirming the diagnosis in clinical cases of 
COVID-19. ${ }^{38}$ As inclusion criterion for diagnosis, at least two symptoms (fever, respiratory symptoms, gastrointestinal symptoms or fatigue), combined with laboratory tests (normal or low white blood cell count, and increased c-reactive protein) and an abnormal chest x-ray have been used. While other infectious diseases, such as influenza, should be excluded before the patients were diagnosed with COVID-19. ${ }^{39}$

\section{Approaches to Curtail SARS-CoV-2 Suppression and Mitigation Approach}

Researchers and scientists experienced about spread and aid recovery of the COVID-19 pandemic with a condition of great uncertainty. Circling the unknowns, inching toward truth through argument and experiment is how progress has been made (Table 2). ${ }^{40}$ However, with limited understanding of SARS-CoV-2, current attempts at controlling SARS-CoV-2 spread are focused social measures that reduce rates of viral transmission in the community such as social distancing and self-isolation by symptomatic individuals. ${ }^{41}$ The effect of these measurements are broadly classified as an approach to suppress transmission and to mitigate devastating health impact. The suppressing approach aims are to reduce endogenous transmission. ${ }^{42}$ Under this approach, the goal is to prevent subsequent propagation of virus through effective exposure of susceptible hosts by maintaining control measures in place for certain periods. On the one hand, the mitigating approach aims to reduce the growth rate of the epidemic to ensure the disease burden does not overwhelm healthcare systems. $^{43}$

\section{Immunity Response and Immunity Passport}

A timely, localized, and well-coordinated immune response presents the first line of physiological defense against SARS-CoV-2 infection. In brief, innate immune response involves leukocytes such as neutrophils, monocytes, macrophages, eosinophils, mast cells, dendritic cells to recognize pathogen-associated molecular patterns (PAMPs) which in turn are recognized through pattern recognition receptors (PRRs). ${ }^{44}$ Upon recognition, the innate immune system activates cells to attack and to remove pathogens through phagocytosis and cytotoxicity mechanisms. ${ }^{45}$ However, viruses were highly adaptable and have developed ways to switch-off host defense. In such cases, viruses stop MHC molecules from getting to
Table 2 Some of COVID-19 Known Unknowns

\begin{tabular}{|l|l|}
\hline Factors & Available information \\
\hline eg Ibuprofen & $\begin{array}{l}\text { NSAIDS such as Ibuprofen upregulates ACE2 } \\
\text { receptors. }{ }^{48,49} \text { However, the existing literature } \\
\text { does not currently provide conclusive evidence } \\
\text { for or against the use of NSAIDs in the } \\
\text { treatment of COVID-19 patients. } \\
\text { - Caution should be exercised until further } \\
\text { evidence, specific to this infection strain, } \\
\text { emerges. }\end{array}$ \\
\hline ACE-I or ARBs & $\begin{array}{l}\text { Data suggested that ACE2 expression } \\
\text { upregulated in those treated with ACE-I or } \\
\text { ARBs. }{ }^{48} \text { With no conclusive pieces of evidence, } \\
\text { it has been suggested for COVID-19 patients to } \\
\text { remain on these antihypertensive medications. }\end{array}$ \\
\hline Susceptibility to \\
COVID-19
\end{tabular}

Abbreviations: NSAIDS, non-steroidal anti-inflammatory drugs; ACE, angiotensinconverting enzyme; ARBs, angiotensin receptor blockers.

the cell surface to display viral peptides. Once there, they try to escape recognition through the enclosure of genetic material within capsules made of viral proteins and disruption of the transcription and translation inside the infected cells. ${ }^{46}$ Hence, viruses in the absence of cytopathologic damage at the early stages of infection inhibit the induction of acute-phase protein response because early monocytes are not activated. ${ }^{47}$

One of the challenging clinical questions has been why some patients seem particularly susceptible while several other patients remain well and afebrile and yet carrying the virus. Unfortunately, there are no studies on the immune response in infected asymptomatic individuals, the new coronavirus seems to rely on early stealth, somehow delaying the launch of the innate immune system, and inhibiting the production of interferons - those molecules that initially block viral replication. It creates a brief time window in which the virus can replicate unnoticed before the alarm bells start sounding. Those delays cascade: If the innate branch is slow to mobilize, the adaptive branches will also lag. ${ }^{47}$

On the other hand, the hallmark of the adaptive immune system lies in its ability to develop immune memory enabling it to secret specific protective antibodies 
or immunoglobulins over long periods in the apparent absence of the infection. ${ }^{20}$ Immunoglobulins play an important role to point out both an ongoing infection (eg primary immune response) and a previously took place infection (eg secondary immune response). ${ }^{33}$ The rapid and augmented secondary response is due to the recruitment of specific memory cells that arose during the development of the initial clone, but did not mature into antibody-secreting plasma cells. These memory B cells can last decades, hiding out in lymph nodes, the spleen, bone marrow, and the lung, while some circulate in the blood. Upon re-infection by the same pathogen, they swing back into action, taking 2-4 days to differentiate into cells that secrete neutralizing antibodies. ${ }^{20}$

On the contrary, with a potential vaccine coming ahead, many governments are looking for paths out of restrictive physical distancing measures imposed to control the spread of SARS-CoV-2. ${ }^{52}$

As a consequence, at this point in the COVID-19 pandemic, the use of immunity passports (risk-free certificate), which is digital or physical, documents that certify an individual at low risk of acquiring or transmitting SARS-CoV-2 have suggested. ${ }^{53}$ But, an individual might nevertheless carry the virus at similar levels, and for a similar duration, to those previously uninfected, with an unchanged potential for transmission. ${ }^{54,55}$ As with seasonal coronaviruses, COVID-19 patients who have recovered from infection have been found to develop antibodies between 6 and 15 days post disease. ${ }^{33,50}$ Despite limited information on the effect, some governments, including the UK, Estonia, Italy, and Chile have considered immunity passport. $^{53}$

\section{Why Not Immunity Guarantee?}

- Immunity to seasonal coronaviruses is usually relatively short-lived. For instance, studies of survivors of the SARS-CoV epidemic showed that patients who were IgG positive were maintained in $>90 \%$ of the patients for 2 years. ${ }^{56}$ However, another study reported that 6 years later after infection, SARS$\mathrm{CoV}$ antibodies were not detected. ${ }^{57}$

- In many seasonal coronaviruses, an antibody response less correlates in individuals with the asymptomatic or mild disease than in those with severe disease. $^{58}$

- Currently, we do not have evidence that indicates whether people who have recovered from COVID-
19 and have antibodies are protected from a second infection.

Therefore, to know how long the protective immune response against SARS-CoV-2 will last, longitudinal serological studies that follow patients' immunity over an extended period is required.

\section{The Ethical Concern of Immunity Passport}

There is much debate about the use of immunity passports in the response to the COVID-19 pandemic. One of the debating issues with immunity passport has been uncertainties relating to COVID-19 immunity, issues with testing (lack of timely access to laboratory test or vaccination), perverse incentives (to seek out infection), doubtful economic benefits, privacy concerns, and discriminatory access. ${ }^{53}$ Challenges relating to the implementation of immunity passports ought to be met with targeted solutions to maximize their benefit. However, individual-targeted policies predicated on antibody testing, such as immunity passports, are not only impractical given these current gaps in knowledge and technical limitations but also pose considerable equitable and legal concerns, even if such limitations are rectified.

\section{Herd Immunity (or Community Immunity)}

Herd immunity is one of the other strategies proposed by some governments looking for paths out of restrictive physical distancing measures imposed to control the spread of SARS-CoV-2. For example, a trial of implementing this strategy without achieving an estimated proportion of immune individuals for herd immunity threshold in the COVID-19 pandemic was done in the United Kingdom, but was not successful. ${ }^{59}$

A phenomenon called herd immunity is an extrapolated effect of an individual immunity mapped to entire host populations to prevent pathogen transmission dynamics and the success of vaccination campaigns for entire host populations. ${ }^{60}$ Herd immunity exists when a sufficient population have immunity (by vaccination, or natural infection) such that the likelihood of effective contact between infected and susceptible hosts is reduced. ${ }^{6}$

As a consequence, the first infectious individual simultaneously decreases the number of secondary cases generated by the primary case in a completely susceptible population. The central epidemiological questions are 
thus: what proportion of the population should be vaccinated to achieve elimination (in a local program), eradication (in a global program), or a defined level of control? How is this affected by demographic factors (for example, gender?) What is the best age at which to immunize? How does mass immunization affect the age distribution of susceptible individuals particularly in those classes most at risk from serious disease? To answer these questions, we need to understand the variation in transmission dynamics and the acquisition of immunity by individuals in the population.

The concept of herd immunity proposed to reduce the risk of highly exposed populations such as health-care workers or individuals with frequent contact with customers. ${ }^{61}$ Besides, it also help to provide indirect protection for non- or under-vaccinated individuals in the community, such as the immunocompromised and immunologically naïve or newborns by reducing the number of susceptible hosts to a level below the "herd immunity threshold" needed for transmission. ${ }^{62}$ In the simplest analysis, the herd immunity threshold is the critical proportion of the population that must be immunized to achieve the elimination of the epidemics.

For instance, vaccination of $>80 \%$ of the population against smallpox in the late 1970s reduced transmission rates to the level of the virus eradication. ${ }^{63}$ Similarly, the success of child immunization programs for the control of measles and pertussis (92-96\%), mumps (88-92\%), and rubella (84-88\%) in the Western Europe and the United States. ${ }^{64}$

Here is little evidence to suggest that a precise herd immunity threshold for SARS-CoV-2 might be achieved naturally before at least $50 \%$ of the population has become immune. ${ }^{65}$

A question that is often noted here is what it would take to achieve a threshold of population immunity. The WHO marked that programmed vaccination as a first step towards achieving vaccine-induced herd immunity and estimates to save up to 3 million lives each year worldwide from infectious diseases that pose significant global health and economic burdens. ${ }^{66}$ Naturally acquired protective immunity also helps to create herd immunity; however, it is necessary to achieve the social optimum such as individuals that are at risk of severe complications. ${ }^{65}$ But, most vaccines are suited for yielding the indirect effect of herd immunity to protect communities at large, particularly targeting highly vulnerable populations. ${ }^{65}$

A successful indirect effect of herd immunity, however, can be achieved when targeted vaccination and changes in epidemic cycles in response to vaccination is indicated. In concern, in the focus of vaccine development, some recent work suggests transmission-blocking vaccines rather disease-only blocking vaccines to maximize the safest outcomes. ${ }^{60}$

Vaccine-induced herd immunity is also an important concept of epidemic theory regarding:

- A subsidy to decrease the cash cost of vaccination,

- A nationwide public vaccination campaign to lower the psychological cost of vaccination, and

- To minimize the side-effects of vaccines. ${ }^{67}$

On the other hand, theory can define the level of vaccination coverage required for the prevention and elimination of epidemics, but success depends on:

- Socioeconomic status and universal access to affordable health. ${ }^{62,68}$

- Individuals of lower socioeconomic status often forgo vaccinations due to accessibility reasons.

- Besides, non-vaccinated and susceptible people facilitate transmission to others who lack accessibility, thus breaking the protective barrier herd immunity provides.

- Social motivational issues and Public policy. ${ }^{69,70}$

- As vaccines are in all likelihood to provide a safer option than the risk of serious disease arising from natural infection, but also they are almost invariably carrying some risk to the individual and especially the lack of a long-term safety. ${ }^{65}$ Such concerns could spread more easily among people already suspicious of medical authority, including minority communities. For example, the history of medical experiments such as the infamous federal Tuskegee Study, which involved 600 black men and failed to treat that syphilis. ${ }^{71}$ However, there, was no evidence that researchers had informed them of the study or its real purpose. The men had been misled and had not been given all the facts required to provide informed consent. This indicates a need for effectively communication of the concept of vaccine and vaccine-induced herd immunity to counter anti-vaccination proponents through addressing the individual benefit (ie the more vaccinated people in your environment, the more likely you are protected without vaccination) and/or the social benefit (ie If many individuals are 
vaccinated, the immune population will protect unvaccinated individuals).

Thus, to reach the goal of protection from disease and eradication of COVID-19 pandemic through vaccination, governments, scientists, and citizens of the world will have to commit resources equivalent to the diversity and abundance of the pandemic we have been strangled to fight. Besides, such strategies decrease the probability of freeriding motives, in which individuals profit from the protection provided by a well-vaccinated society without contributing to herd immunity themselves. ${ }^{72}$

\section{The Infeasibility of Herd Immunity}

The estimate of herd immunity, however, has been relayed on several key assumptions that questioned its feasibility in the COVID-19 pandemic. A large percentage of the population will need to be immune against the disease (through infection or vaccination) before herd immunity will be achieved.

It is not known when that will happen, but it will depend on how many people develop immunity after COVID-19 infection, how soon a COVID-19 vaccine is available, how many vaccine doses will be available for distribution, and how many people get vaccinated. It is not yet known if having this disease confers immunity to future infection, and if so, for how long.

\section{Heterogeneity and COVID-19}

COVID-19 outbreak is impacting societies around the world in an unprecedented manner. Despite infection is assumed to spread within a homogeneously mixing community, not everyone, in every place, have been affected in the same way. While there has been no firm explanation, such disparity complications are thought to be induced by heterogeneity such as gender, age-group and behavioral factors. ${ }^{62}$ Hence, considering how the pandemic affects particular groups in the community will help raise the effectiveness of vaccine-induced herd immunity required to eliminate an infection.

\section{Gendered Disparity}

From the evidence of past epidemics, such as MERS-CoV, a higher disease occurrence, and death in men than in women was indicated. ${ }^{73}$ Besides, among SARS-CoV case data reported to WHO from 30 different countries and areas, there appear to be higher numbers of deaths in men. ${ }^{74,75}$ On the contrary, although data were limited so far, the International Health Regulations data show a relatively even distribution of COVID-19 infections between women and men ( $47 \%$ versus $51 \%$, respectively), with some variations across age groups. ${ }^{76}$

Studies indicated that sex differences of humans and animals extend beyond their anatomical physical features to the physiological and metabolic traits that affect important immune system functions, thereby predisposing males and females to respond differently to infectious diseases. ${ }^{73}$ There is a growing body of evidence from the literature showing that antibody responses to viruses are consistently higher levels in females than males. ${ }^{77}$ Hormonal influences on the function of B lymphocytes have been quantified by analyzing immunoglobulin levels. For instance, studies indicated that estrogen enhances $\operatorname{IgG}$ and $\operatorname{IgM}$ production, ${ }^{78}$ while testosterone appears to inhibit in both males and females. ${ }^{79}$

The differences in the immune systems of males and females are also related to the expression of $\mathrm{Y}$ and $\mathrm{X}$-linked genes. It is reported that there are disproportionately more messenger RNAs located on the $\mathrm{X}$ chromosome than on any autosomal chromosome. Besides, as several immune-related genes are encoded on the $\mathrm{X}$ chromosome and there is some evidence of greater activation of X-linked genes in immune cells from females than males. ${ }^{80}$

\section{Behavioral Characteristics}

It is known that lifestyle habits play crucial roles in shaping the health status of an individual. For instance, tobacco smoking is a known risk factor for many respiratory infections and increases the severity of respiratory diseases. ${ }^{81}$ In this case, smoking can upregulate ACE2 that has been identified as a functional receptor used by coronaviruses for entry into the human cells, including SARS-CoV and COVID-19. ${ }^{18,19}$ ACE2 produces surfactant which reduces surface tension, thus preventing alveoli from collapsing, and hence are critical to the gas exchange function of the lung. ${ }^{82}$ In this regard, men are believed to partake in unhealthy habits (eg, alcohol and tobacco consumption) that are associated with developing chronic diseases. Studies have shown that smokers were also noted to have higher mortality in the previous MERS-CoV outbreak. ${ }^{83,84}$ Although the effects of smoking on Corona Virus Disease 2019 (COVID-19) are currently unknown, studies have indicated a higher rate of deaths in current and former smokers. ${ }^{85,86}$ 


\section{Age-Dependent Factors}

Age-dependent mortality risk is estimated to be as high as 0.48 for people older than 80 years. ${ }^{87}$ Recent numerical studies suggest that the male-to-female ratio for deaths was observed higher for 50-65 year-olds. ${ }^{88}$ Although data were limited so far, sex-disaggregated preliminary analysis of the data from the International Health Regulations shows a relatively even distribution of infections between women and men (47\% versus 51\%, respectively), with some variations across age groups. ${ }^{89}$ Besides, based on shreds of evidence, COVID-19 cases have been less susceptible in children compared to adults regardless of gender differences. ${ }^{31}$ These predictions, however, must be accepted with caution at present. Because the observed data reporting in infection rates and deaths among late teenage and adult age groups may be artifacts arising probably from skewed case reporting. ${ }^{76,87}$ This might also since the relationship between age and clinical symptoms differ with comorbidities. ${ }^{87}$ Therefore, any sexdisaggregated interpretation across age groups and countries is better to be with great caution.

\section{Public Health Challenges and COVID-I 9}

To date the COVID-19 pandemic, in the era of a world controlled by technology, has had a strong impact on social and economic life, stretching from physical isolation and social distancing to the enhancement of global famines. $^{37}$ Accordingly, real-time global statistics by Johns Hopkins Center for Systems Science and Engineering (CSSE), globally, as of 16 November 2020, there have been 54,075,995 confirmed cases of COVID19 , including $1,313,919$ deaths. $^{90}$

Despite these figures, confirmed cases and the death toll from COVID- 19 did not reflect official statistics and therefore, likely to be higher than the reported figures. Factors pointed as cause includes 1) lack of a countries test (eg People who have developed COVID-19 symptoms but have not been tested; 2) the asymptomatic phase of the disease has not been tested; 3) some countries may only count hospital deaths, while others have started to include deaths in homes or due to delays in reporting; 4) some countries report the daily number of tests; while others report the number of new people tested on each day. ${ }^{91}$

This distinction was important as people may be tested many times, and the number of tests a person is likely to vary across countries. Also, beyond the deaths of people, it was known that fear reduces human immunity and makes people susceptible to a wide range of diseases, and causes a high level of stress; often with longer-term consequences. ${ }^{92}$ COVID-19 was not only challenging global health systems but testing our common humanity.

Moreover, the importance of community, both culturally and in the country's development strategy made it hard to respect WHO recommendations on regular hand washing, social distancing, and avoiding crowded places in many parts of the world. ${ }^{93}$ Limited PPE resources, healthcare workers for SARS-CoV-2 testing, critical care beds and laboratory capacity have been being the most common challenges, particularly to Africa. ${ }^{94}$ For instance, Guinea-Bissau reportedly has no ventilators, while Malawi has 25 intensive-care-unit beds for a population of 17 million. $^{95}$ Corresponding figures for Ethiopia was a total of 557 mechanical ventilators and 570 intensive care unit (ICU) beds for a population of 110 million. ${ }^{96}$

\section{Summary}

In the process of reining COVID-19 through a vaccination program, an emphasis should be placed on policies that protect the most vulnerable individuals in the hopes that herd immunity will eventually be achieved as a process.

Data reporting variations in infection rates and deaths among women and men of different age groups probably skewed. Limited sex-disaggregated preliminary analysis of data from the International Health Regulations shows a relatively even distribution of infections between women and men (47\% versus 51\%, respectively), with some variations across age groups. As a result, the death of gender difference interpretation for COVID-19 across age groups and countries is suggested to be with great caution.

To reach the goal of protection from disease and eradication of COVID-19 pandemic through vaccination, governments, scientists, and citizens of the world will have to commit resources equivalent to the diversity and abundance of the pandemic we have been strangled to fight. COVID-19 has taught us that health is the basis of global wealth and international solidarity is an essential response and a superior approach to isolationism.

Hence, we must be clear about what the alternatives are when evaluating the merits of different ways of tackling this pandemic both in the short term as well as in the long term. In this review, the insights provided based on the results of recent articles about COVID-19 will help raise 
the effectiveness of the treatment policies and preventive measures required to eliminate the COVID-19 pandemic.

\section{Abbreviations}

ACE2, angiotensin-converting enzyme 2; ARBs, angiotensin receptor blockers; CDC, Center for Disease Control and Prevention; CSSE, Center for Systems Science and Engineering; ECF, extracellular fluid; ICU, intensive care unit; IgG, immunoglobulin G; IgM, immunoglobulin M; MERS-CoV, Middle East respiratory syndrome; MEWS, Modified Early Warning Score; PAMPs, pathogenassociated molecular patterns; MHC, major histocompatibility complex; PPE, personal protective equipment; PRRs, pattern recognition receptors; SARS-CoV, severe acute respiratory syndrome coronavirus; TLR, Toll-like receptors; URTI, upper respiratory tract infections.

\section{Acknowledgments}

We are grateful to acknowledge Ms Roza Wami, for all her good will and support through this review.

\section{Author Contributions}

All authors made a significant contribution to the work reported in all these areas; took part in drafting, revising or critically reviewing the article; gave final approval of the version to be published; have agreed on the journal to which the article has been submitted; and agree to be accountable for all aspects of the work.

\section{Funding}

This research received no specific grant from any funding agency in the public or commercial sectors.

\section{Disclosure}

The authors report no conflicts of interest for this work.

\section{References}

1. Porta M, editor. A Dictionary of Epidemiology. Oxford university press; 2014.

2. Qui W, Rutherford S, Mao A, Chu C. The pandemic and its impacts. Health Cult Soc. 2017;9-10.

3. The 'greatest pandemic in history' was 100 years ago - but many of us still get the basic facts wrong. Available from: https://theconversation. com/the-greatest-pandemic-in-history-was-100-years-ago-but-many-of -us-still-get-the-basic-facts-wrong-8984/. Accessed August 12, 2020.

4. Zhu N, Zhang D, Wang W, et al. A novel coronavirus from patients with pneumonia in China. $N$ Engl J Med. 2019.

5. World Health Organization. Coronavirus disease 2019 (COVID-19) situation report. Available from: https://www.who.int/emergencies/dis eases/novel-coronavirus-2019/situationreports/. Accessed October 27, 2020.
6. Randolph HE, Barreiro LB. Herd immunity: understanding COVID-19. Immunity. 2020;52(5):737-741. doi:10.1016/j.immuni.20 20.04.012

7. World Health Organization WHO. Summary of probable SARS cases with onset of illness. Available from: http:/www.who.int/csr/sars/ country/table2004 04 21/en/index.html. Accessed December 4, 2020.

8. He X, Lau EHY, Wu P, et al. Temporal dynamics in viral shedding and transmissibility of COVI-19. Nat Med. 2020.

9. Anfinrud P, Stadnytskyi V, Bax CE, Bax A. Visualizing speech-generated oral fluid droplets with laser light scattering. $N$ Engl J Med. 2020;382(21):2061-2063. doi:10.1056/NEJMc200 7800

10. Zhang H, Kang Z, Gong H, et al. The digestive system is a potential route of 2019-nCov infection: a bioinformatics analysis based on single-cell transcriptomes. BioRxiv. 2020.

11. Wei WE, Li Z, Chiew CJ, Yong SE, Toh MP, Lee VJ. Presymptomatic transmission of SARS-CoV-2 - Singapore, January 23-March 16, 2020. MMWR Morb Mortal Wkly Rep. 2020;69(14):411. doi:10.15585/mmwr.mm6914e1

12. Van Damme W, Dahake R, Delamou A, Ingelbeen B, Wouters E. The COVID-19 pandemic: diverse contexts; different epidemics-how and why? BMJ Glob Health. 2020;5(7):e003098. doi:10.1136/ bmjgh-2020-003098

13. Huang C, Wang Y, Li X, et al. Clinical features of patients infected with 2019 novel coronavirus in Wuhan, China. Lancet. 2020;395 (10223):497-506. doi:10.1016/S0140-6736(20)30183-5

14. Li Q, Guan X, Wu P, et al. Early transmission dynamics in Wuhan, China, of novel coronavirus-infected pneumonia. $N$ Engl $J$ Med. 2020;382(13):1199-1207. doi:10.1056/NEJMoa2001316

15. Zhang T, Wu Q, Zhang Z. Probable pangolin origin of SARS-CoV-2 associated with the COVID-19 outbreak. Curr Biol. 2020;30: 1346-1351.

16. Karthick R, Meenalochini P, Dawood MS, Akram M, Selvaprasanth P. A Geographical Review: Novel Coronavirus (COVID-19) Pandemic.

17. Natural News. Coronavirus: a bioweapon or Chinese experiment gone wrong. Available from: http://www.naturalnews.com/2020coronavirus-bioweapon-chinese-vaccineexperiment-gone-wrongpshuttle-sn-genesequence.html. Accessed December 4, 2020.

18. Zhou P, Yang X-L, Wang X-G, et al. A pneumonia outbreak associated with a new coronavirus of probable bat origin. Nature. $2020 ; 1-4$.

19. Jia HP, Look DC, Shi L, et al. ACE2 receptor expression and severe acute respiratory syndrome coronavirus infection depend on differentiation of human airway epithelia. $J$ Virol. 2005;79 (23):14614-14621. doi:10.1128/JVI.79.23.14614-14621.2005

20. Sherwood L. Human Physiology: From Cells to Systems. 7th ed. Cengage learning; 2015.

21. Yang JK, Feng Y, Yuan MY, et al. Plasma glucose levels and diabetes are independent predictors for mortality and morbidity in patients with SARS. Diabetic Med. 2006;23(6):623-628. doi:10.1111/j.14645491.2006.01861.x

22. Wang D, Hu B, Hu C, et al. Clinical characteristics of 138 hospitalized patients with 2019 novel coronavirus-infected pneumonia in Wuhan, China. JAMA. 2020.

23. Monteil V, Kwon H, Prado P, Hagelkrüys A, Wimmer RA. Inhibition of SARS-CoV-2 infections in engineered human tissues using clinical-grade soluble human ACE2. Cell. 2020;181(4):905-913.e7. doi:10.1016/j.cell.2020.04.004

24. Turner AJ, Hiscox JA, Hooper NM. ACE2: from vasopeptidase to SARS virus receptor. Trends Pharmacol Sci. 2004;25(6):291-294. doi:10.1016/j.tips.2004.04.001

25. Li W, Moore MJ, Vasilieva N, et al. Angiotensin-converting enzyme 2 is a functional receptor for the SARS coronavirus. Nature. 2003;426(6965):450-454. doi:10.1038/nature02145 
26. Zheng YY, Ma YT, Zhang JY. COVID-19 and the cardiovascular system. Nat Rev Cardiol. 2020;17(5):259-260. doi:10.1038/s41569020-0360-5

27. American physiology Societies. Avalaible from: https://www.physiol ogy.org/publications/news/the-physiologistmagazine/2020/septem ber/the-physiology-of-covid-19?SSO=Y[OnlineResource]. Accessed December 4, 2020.

28. Eriksson K, Jonsson M, Sjöstrand J. Markov chains on graded posets. Order. 2018;35(1):93. doi:10.1007/s11083-016-9420-1

29. Mizumoto K, Kagaya K, Zarebski A, Chowell G. Estimating the asymptomatic proportion of coronavirus disease 2019 (COVID-19) cases on board the diamond princess cruise ship, Yokohama, Japan, 2020. Euro Surveill. 2020;25(10).

30. Yang X, Yu Y, Xu J, et al. Clinical course and outcomes of critically ill patients with SARS-CoV-2pneumonia in Wuhan, China: a single-centered, retrospective, observational study. Lancet Respir Med. 2020;8(5):475-481. doi:10.1016/S2213-2600(20)30079-5

31. Ludvigsson JF. Systematic review of COVID-19 in children shows milder cases and a better prognosis than adults. Acta Paediatr. 2020;109(6):1088-1095. doi:10.1111/apa.15270

32. World Health Organization. Coronavirus Disease 2019 (COVID-19) Situation Report - 78. Geneva: WHO; 2020.

33. Yang JK, Lin SS, Ji XJ, Guo L-M. Binding of SARS coronavirus to its receptor damages islets and causes acute diabetes. Acta Diabetol. 2010;47(3):193. doi:10.1007/s00592-009-0109-4

34. Li T, Wei C, Li W, Hongwei F, Shi J. Beijing union medical college hospital on" pneumonia of novel coronavirus infection" diagnosis and treatment proposal (V2. 0). Med J Peking Union Med Coll Hosp. 2020.

35. $\mathrm{Hu} \mathrm{H}$, Yao N, Qiu Y. Comparing rapid scoring systems in mortality prediction of critical ill patients with novel coronavirus disease. Acad Emerg Med. 2020;27(6):461-468. doi:10.1111/acem.13992

36. Yasin SM, Muzaini K, Samsudin EZ, Selamat MI, Ismail Z. Are our healthcare workers well protected during COVID-19? Learning from current experiences and challenges. J Clin Health Sci. 2020;5 (2):4-18. doi:10.24191/jchs.v5i2.8967

37. Millán-Oñate $\mathrm{J}$, Rodriguez-Morales AJ, Camacho-Moreno G, Mendoza-Ramírez H, Rodríguez-Sabogal IA, Álvarez-Moreno C. A new emerging zoonotic virus of concern: the 2019 novel coronavirus (SARS CoV-2). Infection. 2020;24(3):187-192. doi:10.22354/ in.v24i3.848

38. Roser M, Ritchie H, Ortiz-Ospina E, Hasell J. Coronavirus Disease (Covid-19)-Statistics and Research. Our World in Data; 2020.

39. Dong Y, Mo XI, Hu Y, et al. Epidemiological characteristics of 2143 pediatric patients with 2019 coronavirus disease in China. Pediatrics. 2020;16:16.

40. Roberts S. Embracing the uncertainties. The New-York Times; 2020. Available from: https:/www.nytimes.com/2020/04/07/science/corona virus-uncertainty-scientific-trust.html. Accessed August, 2020.

41. ClinicalTrials.gov. ClinicalTrials.gov is a database of privately and publicly funded clinical studies conducted around the world. Available from: https://www.clinicaltrials.gov/. Accessed October, 2020 .

42. Liu W, Tao ZW, Lei W, et al. Analysis of factors associated with disease outcomes in hospitalized patients with 2019 novel coronavirus disease. Chin Med J. 2020.

43. Murad MH, Asi N, Alsawas M, Alahdab F. New evidence pyramid. Evid Based Med. 2016;21(4):125-127. doi:10.1136/ebmed-2016-110401

44. Williams AE. Basic Concepts in Immunology. In: Immunology: Mucosal and Body Surface Defences. Chichester, UK: John Wiley \& Sons, Ltd; 2011:1-19.

45. Tosi MF. Innate immune responses to infection. J Allergy Clin Immunol. 2005;116(2):241-249. doi:10.1016/j.jaci.2005.05.036

46. Kowalik MM, Trzonkowski P, Łasińska-Kowara M, Mital A, Smiatacz T. COVID-19 - toward a comprehensive understanding of the disease. Cardiol J. 2020;27(2):99-114. doi:10.5603/CJ.a2020.0065
47. Yong E. Immunology is where intuition goes to die. The Atlantic, which is too bad because we really need to understand how the immune system reacts to the coronavirus. Available from: https:// www.theatlantic.com/health/archive/2020/08/covid-19-immunity-isthe-pandemics-central-mystery/614956/. Accessed November, 2020.

48. Fang L, Karakiulakis G, Roth M. Are patients with hypertension and diabetes mellitus at increased risk for COVID-19 infection? Lancet Respir Med. 2020;8(4):e21. doi:10.1016/S2213-2600(20)30116-8

49. Shi Y, Wang Y, Shao C, et al. Giuseppe Ippolito \& Gerry Melino COVID-19 infection: the perspectives on immune responses. Cell Death Differ. 2020;27(1451-1454):1451-1454. doi:10.1038/s41418020-0530-3

50. Racine R, Winslow GM. IgM in microbial infections: taken for granted? Immunol Lett. 2009;125(2):79-85. doi:10.1016/j.imlet.20 09.06 .003

51. Kakodkar P, Kaka N, Baig M. A comprehensive literature review on the clinical presentation, and management of the pandemic coronavirus disease 2019 (COVID-19). Cureus. 2020. doi:10.7759/cureus. 7560

52. Phelan AL. COVID-19 immunity passports and vaccination certificates: scientific, equitable, and legal challenges. Lancet. 2020;395 (10237):1595-1598. doi:10.1016/S0140-6736(20)31034-5

53. Brown RC, Kelly D, Wilkinson D, Savulescu J. The scientific and ethical feasibility of immunity passports. Lancet Infect Dis. 2020. doi:10.1016/S1473-3099(20)30766-0

54. Gao Q, Bao L, Mao H, et al. Development of an inactivated vaccine candidate for SARS-CoV-2. Science. 2020;369(6499):77-81. doi:10. 1126/science.abc1932

55. Callow KA, Parry HF, Sergeant M, Tyrrell DA. The time course of the immune response to experimental coronavirus infection of man. Epidemiol Infect. 1990;105(2):435-446. doi:10.1017/S0950268800 048019

56. Wu LP, Wang NC, Chang YH, et al. Duration of antibody responses after severe acute respiratory syndrome. Emerg Infect Dis. 2007;13 (10):1562. doi:10.3201/eid1310.070576

57. Peiris JS, Yuen KY, Osterhaus AD, Stohr K. The severe acute respiratory syndrome. $N$ Engl J Med. 2003;349(25):2431-2441. doi:10.1056/NEJMra032498

58. Seow J, Graham C, Merrick B, et al. Longitudinal evaluation and decline of antibody responses in SARS-CoV-2 infection. medRxiv. 2020 .

59. Pollock AM, Roderick P, Cheng K, Pankhania B. Covid-19: why is the UK government ignoring WHO's advice? Available from: https:// www.bmj.com/content/368/bmj.m1284. Accessed November, 2020.

60. Metcalf CJ, Ferrari M, Graham AL, Grenfell BT. Understanding herd immunity. Trends Immunol. 2015;36(12):753-755. doi:10.1016/j. it.2015.10.004

61. D'Souza G, Dowdy D. What's Herd Immunity and How Can We Achieve It with COVID-19. Johns Hopkins School of Public Health Expert Insights; 2020.

62. Anderson RM, May RM. Vaccination and herd immunity to infectious diseases. Nature. 1985;8(6044):323-329.

63. Jones DB. Government of Canada immunization and vaccinepreventable diseases-staying protected. Available from: https:// www.canada.ca/content/dam/phac-aspc/migration/phac-aspc /cphorsphc-respcacsp/2013/assets/pdf/2013-eng.pdf. Accessed November, 2020

64. Centers for Disease Control and prevention. Prevention of acquired immune deficiency syndrome (AIDS): report of inter-agency recommendations. MMWR Morb Mortal Wkly Rep. 1983;32:1-125.

65. Fontanet A, Cauchemez S. COVID-19 herd immunity: where are we? Nat Rev Immunol. 2020;20(10):583-584. doi:10.1038/s41577-02000451-5

66. World Health Organization Media Center Immunization Coverage. Available from: http://www.who.int/mediacentre/factsheets/fs378/en/. Accessed October 20, 2020. 
67. Lim W, Zhang P. Herd immunity and a vaccination game: an experimental study. PLoS One. 2020;5.

68. Meyer M. The ethics of universal health care in the United States. Reflect Healthcare Manage. 2017;1(1):10.

69. Mallory ML, Lindesmith LC, Baric RS. Vaccination-induced herd immunity: successes and challenges. $J$ Allergy Clin Immunol. 2018;142(1):64-66. doi:10.1016/j.jaci.2018.05.007

70. Betsch C, Böhm R, Korn L, Holtmann C. On the benefits of explaining herd immunity in vaccine advocacy. Nat Hum Behav. 2017;1 (3):1-6. doi:10.1038/s41562-017-0056

71. Centers of disease control and prevention (CDC). U.S. public health service syphilis study at Tuskegee. Available from: https://www.cdc. gov/tuskegee/timeline.htm. Accessed November, 2020.

72. Verelst F, Willem L, Kessels R, Beutels P. Individual decisions to vaccinate one's child or oneself: a discrete choice experiment rejecting free-riding motives. Soc Sci Med. 2018;207:106-116. doi:10. 1016/j.socscimed.2018.04.038

73. Mobaraki K, Ahmadzadeh J. Current epidemiological status of Middle East respiratory syndrome coronavirus in the world from 1.1. 2017 to 17.1. 2018: a cross-sectional study. BMC Infect Dis. 2019;19(1):1-5. doi:10.1186/s12879-019-3987-2

74. WHO. Summary table of SARS by country 1 november 2002-7 august 2003; 2003. Available from: http://www.who.int/entity/csr/ sars/country/country2003_08_15.pdf. Accessed November, 2020.

75. Leung GM, Hedley AJ, Ho LM, et al. The epidemiology of severe acute respiratory syndrome in the 2003 Hong Kong epidemic: an analysis of all 1755 patients. Ann Intern Med. 2004;141(9):662. doi:10.7326/0003-4819-141-9-200411020-00006

76. World Health Organization. Gender and COVID-19: Advocacy Brief, 14 May 2020. World Health Organization; 2020.

77. Butterworth M, McClellan B, Allansmith M. Influence of sex in immunoglobulin levels. Nature. 1967;214(5094):1224-1225. doi:10. $1038 / 2141224 \mathrm{a} 0$

78. Kanda N, Tamaki K. Estrogen enhances immunoglobulin production by human PBMCs. J Allergy Clin Immunol. 1999;103(2 Pt 1): 282-288.

79. Kanda N, Tsuchida T, Tamaki K. Testosterone inhibits immunoglobulin production by human peripheral blood mononuclear cells. Clin Exp Immunol. 1996;106(2):410-415. doi:10.1046/j.1365-2249.1996. d01-842.x

80. Pinheiro I, Dejager L, Libert C. X-chromosome-located microRNAs in immunity: might they explain male/female differences? The $\mathrm{X}$ chromosome-genomic context may affect X-located miRNAs and downstream signaling, thereby contributing to the enhanced immune response of females. Bioessays. 2011;33(11):791-802. doi:10.1002/ bies. 201100047

81. Brake SJ, Barnsley K, Lu W, McAlinden KD, Eapen MS, Sohal SS. Smoking Upregulates Angiotensin-Converting Enzyme-2 Receptor: A Potential Adhesion Site for Novel Coronavirus SARS-Cov-2 (Covid-19). 2020.
82. Dobbs LG. Pulmonary surfactant. Inhibition of SARS-CoV-2 infections in engineered human tissues using clinical-grade soluble human ACE2. Annu Rev Med. 1989;40(1):431-446. doi:10.1146/annurev. me.40.020189.002243

83. Park JE, Jung S, Kim A, Park J-E. MERS transmission and risk factors: a systematic review. BMC Public Health. 2018;18(1):574. doi:10.1186/s12889-018-5484-8

84. Arcavi L, Benowitz NL. Cigarette smoking and infection. Arch Intern Med. 2004;164(20):2206-2216. doi:10.1001/archinte.164.20.2206

85. Zhou F, Yu T, Du R, Fan G, Liu Y, Liu Z. Clinical course and risk factors for mortality of adult inpatients with COVID-19 in Wuhan, China: a retrospective cohort study. Lancet. 2020;395(10229): 1054-1062. doi:10.1016/S0140-6736(20)30566-3

86. Zhang JJ, Dong X, Cao YY, Yuan YD, Yang YB, Yan YQ. Clinical characteristics of 140 patients infected with SARS-CoV-2 in Wuhan, China. Allergy. 2020;75(7):1730-1741. doi:10.1111/all.14238

87. Li H, Wang S, Zhong F, et al. Age-dependent risks of incidence and mortality of COVID-19 in Hubei Province and other parts of China. Front Med. 2020;7:190.

88. Assessment RR. Outbreak of Novel Coronavirus Disease 2019 (COVID-19): Increased Transmission Globally-Fifth Update What is New in This Update? 2019.

89. The Novel Coronavirus Pneumonia Emergency Response Epidemiology Team. The epidemiological characteristics of an outbreak of 2019 novel coronavirus diseases (covid-19) - China, 2020. Chin CDC Weekly. 2020;2(8):113-122. doi:10.46234/ccdcw2020.032

90. Nishiura H. Case fatality ratio of pandemic influenza. Lancet Infect Dis. 2020;382(7):2061-2063. doi:10.1016/S1473-3099(10)70120-1

91. COVID-19 dashboard by the Center for Systems Science and Engineering (CSSE) at Johns Hopkins University (JHU).

92. Hyams KC, Murphy FM, Wessely S, et al. Responding to chemical, biological, or nuclear terrorism: the indirect and long-term health effects may present the greatest challenge. $J$ Health Polit Policy Law. 2002;27(2):273-291. doi:10.1215/03616878-27-2-273

93. Ogunleye OO, Basu D, Mueller D, Sneddon J, Seaton RA. Response to the novel corona virus (COVID-19) pandemic across Africa: successes, challenges and implications for the future. Front Pharmacol. 2020.

94. WHO. Electronic state parties self-assessment annual reporting. Available from: https://extranet.who.int/e-spar. Accessed November, 2020.

95. Elovainio R, Pick A. COVID-19 and beyond: how can Africa's health systems cope? OECD development matters, 7 april 2020. Available from: https://oecd-development-matters.org/2020/04/07/ covid-19-andbeyond-how-can-africas-health-systems-cope/. Accessed November, 2020.

96. Shigute Z, Mebratie AD, Alemu G, Bedi A. Containing the spread of COVID-19 in Ethiopia. J Glob Health. 2020;10(1). doi:10.7189/ jogh.10.010369
Risk Management and Healthcare Policy

\section{Publish your work in this journal}

Risk Management and Healthcare Policy is an international, peerreviewed, open access journal focusing on all aspects of public health, policy, and preventative measures to promote good health and improve morbidity and mortality in the population. The journal welcomes submitted papers covering original research, basic science, clinical \& epidemiological studies, reviews and evaluations, guidelines, expert opinion and commentary, case reports and extended reports. The manuscript management system is completely online and includes a very quick and fair peer-review system, which is all easy to use. Visit http://www.dovepress.com/testimonials.php to read real quotes from published authors. 